Check for updates

Cite this: Nanoscale Adv., 2020, 2, 463

\title{
Nanoscale lipid vesicles functionalized with a nitro- aniline derivative for photoinduced nitric oxide (NO) delivery $\dagger$
}

\author{
Nancy Sharma, (D) a Ajay Kumar Dhyani, (D) ${ }^{\mathrm{b}}$ Srujan Marepally (D) \\ and D. Amilan Jose $(\mathbb{D}$ *a
}

\begin{abstract}
Nanoscale vesicles functionalized with a nitric oxide (NO) releasing molecule 4-nitro-3-(trifluoromethyl) aniline have been reported. The new NO-nano-vesicular donor material shows an effective photorelease of NO upon irradiation with blue light at $410 \mathrm{~nm}$. The kinetics of NO release has been monitored by using simple spectroscopic techniques such as UV-Vis and fluorescence methods. Colorimetric Griess assay and fluorescence DAF assay have been used for the detection and quantification of NO released from vesicles. This new vesicular nanoscale NO donor has the advantages of facile preparation in water, capable of releasing $\mathrm{NO}$ in a pure aqueous medium, photo-controlled NO release, biocompatibility and capacity to modulate the NO donor loading to achieve an essential amount of NO.
\end{abstract}

Received 24th August 2019

Accepted 19th November 2019

DOI: 10.1039/c9na00532c

rsc.li/nanoscale-advances

nitrobenzene related compounds is very attractive; however, it has been scarcely explored for the effective release of NO under biological conditions.

It is also equally important to design a donor that should release NO precisely to a specific site, where it is needed and when it is required. As an alternative to small NO releasing molecules (NORMs), many strategies incorporating NO donors within polymer matrices, ${ }^{5}$ microspheres, nanoparticles, ${ }^{6}$ supramolecular scaffolds, ${ }^{7,8}$ gels, ${ }^{9}$ nanofibrous non-woven materials, ${ }^{10}$ and silicone rubber $^{11}$ have been reported for temporal and spatial control over NO release. Although many NO releasing donor systems have been developed, controlled release and site specificity are the major challenges due to the fast diffusion and low molecular weight of NO. ${ }^{12}$ The clinical applications of most of the available low-molecular-weight NO donors are facing major challenges such as stability, poor bioavailability, a burst release profile and short half-life. These hurdles may be evaded by using nano-scale liposome modified NO donors.

Vesicles are site specific, biocompatible and prolong the release and circulation time. Previously, small molecule based NO releasing donor compounds such as trans $-\mathrm{Cr}(\mathrm{L})(\mathrm{ONO}) 2^{+}(\mathrm{L}$ $=$ cyclam $)^{13}$ (activated by light), spermine- $\mathrm{NO}^{14}$ (activated by heat) and $\mathrm{N}$-diazeniumdiolate- $\mathrm{NO}^{15}$ (activated by $\mathrm{pH}$ ), encapsulated within liposomes have been used for the control release of NO. ${ }^{16}$ However, the encapsulation of NO donors into liposomes has some disadvantages such as difficulty in controlling the NO payload and every time the liposomal solution needs to be passed through a sephadex column to eliminate solute that might have permeated through the lipid membrane.

Herein, we describe an alternative approach to obtaining NO-releasing liposome containing nitrobenzene based NO 
donor with attention towards easy preparation, stability and light triggered delivery. We opted to incorporate amphiphilic NO donors directly into liposomes via a self-assembly approach rather than encapsulating within liposomes.

Recently, 4-nitro-3-(trifluoromethyl)aniline (NTA) based NO donors chemically incorporated into calixarene, Pt-nanoparticle and cellulose modified NO donors have been reported ${ }^{17-19}$ However, NO-releasing nano-scaffolds containing NTA with good biocompatibility and stability in physiological media are rarely reported. ${ }^{20,21}$ This prompted us to investigate the NO releasing behaviour of NTA in a nanoscale vesicle surface. Vesicles are site specific and provide an opportunity to modulate the NO-release behaviour of NTA.

In this study, we demonstrate the potential of nanoscale liposomes that incorporate nitrobenzene derivative NTA as an effective NO-releasing nanoscale material for the controlled delivery of NO in a precise amount.

\section{Experimental section}

\section{Instrumentation and methods}

${ }^{1} \mathrm{H}$ NMR was performed on a Bruker Avance $400 \mathrm{MHz}$. The mass spectrum was recorded on a Waters Q-Tof mass spectrometer. UV absorption spectra were recorded on an Evolution 201 UVVis spectrophotometer using quartz cells of $1.0 \mathrm{~cm}$ path length. A Cary Eclipse fluorescence spectrophotometer was used to record the fluorescence spectra. FT-IR experiments were performed by using a SHIMADZU Infrared spectrophotometer.

\section{Materials and reagents}

Hexadecylamine, 5-chloro-2-nitrobenzotrifluoride, and 1,2dipalmitoyl-sn-glycero-3-phosphocholine (DPPC) were purchased from Sigma-Aldrich, and silica gel (100-200 mesh) was purchased from S.D Fine Chemicals Private Limited. Other chemicals were purchased from Loba Chemie or Merck Limited unless mentioned otherwise. Solvents used were analytically pure and used without further purification.

\section{Synthesis of $N$-hexadecyl-4-nitro-3-(trifluoromethyl)aniline} (Amp-NTA)

Hexadecylamine (5.348 g, $22.15 \mathrm{mmol})$ and $\mathrm{Na}_{2} \mathrm{CO}_{3}(2.347 \mathrm{~g}$, $22.15 \mathrm{mmol}$ ) were refluxed in $50 \mathrm{~mL}$ of ethanol for 20 minutes. 5-Chloro-2-nitrobenzotrifluoride (645 $\mu \mathrm{L}, 4.43 \mathrm{mmol})$ was then added and the mixture was kept under continuous stirring for 3 days. After cooling down to ambient temperature, the resulting suspension was filtered and concentrated by rotary evaporation. The crude product was extracted with chloroform and purified by column chromatography $\left(\mathrm{CHCl}_{3}\right.$ : hexane, $\left.1: 1\right)$ using silica gel (100-200 mesh). The compound Amp-NTA was obtained as a yellow colored powder. Yield $=1.073 \mathrm{~g}$ (56.2\%). Elem anal. calc. for $\mathrm{C}_{23} \mathrm{H}_{37} \mathrm{~F}_{3} \mathrm{~N}_{2} \mathrm{O}_{2}$ : C 64.16; $\mathrm{H}$ 8.66; $\mathrm{N} \mathrm{6.51;} \mathrm{O} \mathrm{7.43;} \mathrm{found:} \mathrm{C}$ 64.60; H 8.21; N 6.35; O 7.18. ${ }^{1} \mathrm{H}-\mathrm{NMR}\left(\mathrm{CDCl}_{3}\right): \delta 8.02(\mathrm{~d}, 1 \mathrm{H})$, $6.86(\mathrm{~d}, 1 \mathrm{H}), 6.63(\mathrm{dd}, 1 \mathrm{H}), 4.56(\mathrm{~s}, 1 \mathrm{H}), 3.21(\mathrm{q}, 2 \mathrm{H}), 1.66(\mathrm{~m}$, $2 \mathrm{H}), 1.41(\mathrm{t}, 2 \mathrm{H}), 1.26(\mathrm{~s}, 24 \mathrm{H}), 0.88(\mathrm{t}, 3 \mathrm{H}) \mathrm{ppm} .{ }^{19} \mathrm{~F}-\mathrm{NMR}$ $\mathrm{CD}_{3} \mathrm{OD}: \delta(\mathrm{ppm})-60.37 .{ }^{13} \mathrm{C}-\mathrm{NMR} \mathrm{CD} \mathrm{Cl}_{3} \mathrm{Cl} \delta(\mathrm{ppm}) 13.83,22.07$, $31.28,28.71$, 29.03, 26.38, 42.29, 121.13, 124.75, 129.74, 133.26,
153.14. ESI-MS $m / z$ : calculated 430.56; found $[\mathrm{M}+\mathrm{H}]^{+} 431.30$. HR-MS: $[\mathrm{M}+\mathrm{H}]^{+}$calculated: 431.2885; observed: 431.2887 .

\section{Preparation of vesicles Ves-NTA}

$3.67 \mathrm{mg}(5 \mu \mathrm{mol})$ of 1,2-dipalmitoyl-sn-glycero-3-phosphocholine (DPPC) was dissolved in $1 \mathrm{~mL}$ of chloroform and $96.35 \mu \mathrm{L}$ of Amp-NTA in $\mathrm{CHCl}_{3}\left(2.234 \mathrm{mg} \mathrm{mL}{ }^{-1}\right)$ was added to the above lipid solution. The clear solution was dried completely under reduced pressure to form a thin dry film. It was rehydrated with $5 \mathrm{~mL}$ of $10 \mathrm{mM}$ phosphate buffer at $\mathrm{pH}=7.4 \mathrm{and}^{20}$ heated up to $60{ }^{\circ} \mathrm{C}$ with sonication for $60 \mathrm{~min}$ to yield a turbid multilamellar lipid suspension. Nanoscale liposomes were obtained by extrusion through a polycarbonate membrane with a pore size of $0.1 \mu \mathrm{m}$ using an Avanti mini extruder. The vesicles were stable over a week if stored under ice-cold conditions, and the vesicles exposed to daylight over a period of time at RT were unstable and precipitated over time. Ves-NTA was assumed to be free of impurities; therefore the vesicle solution was not purified.

\section{NO release studies of Amp-NTA by UV-Vis absorption spectroscopy}

UV-Vis spectra were recorded for a $2 \mathrm{~mL}$ solution of Amp-NTA in methanol $(47.10 \mu \mathrm{M})$ upon irradiation with light of different wavelengths $(254 \mathrm{~nm}, 365 \mathrm{~nm}$ and $410 \mathrm{~nm})$. The solution in a quartz cuvette of $1 \mathrm{~cm}$ path-length. The irradiation experiments was performed by placing the light source at a distance of $1 \mathrm{~cm}$ from the quartz cuvette. Spectral changes indicate that NO was released from Amp-NTA. The change or decrease in absorbance $\left(\lambda_{\max }\right)$ at $383 \mathrm{~nm}$ was monitored to determine the NO release.

\section{NO release studies of Ves-NTA by UV-Vis absorption spectroscopy}

UV-Vis spectra were recorded for $2 \mathrm{~mL}$ of Ves-NTA in PB (10 $\mathrm{mM})$. The solution in a quartz cuvette of $1 \mathrm{~cm}$ path-length. The irradiation was performed with blue light $(410 \mathrm{~nm}, 3 \mathrm{~W})$ by placing the light source at a distance of $4 \mathrm{~cm}$ from the quartz cuvette. The spectrum was recorded at regular time intervals for 3 h. A change in the UV-Vis spectra indicates that NO was released from Ves-NTA in a pure aqueous medium.

\section{Griess assay with Amp-NTA}

NO release was quantified by Griess assay. Accordingly, a stock Griess reagent $(800 \mathrm{mg}$ ) was prepared by dissolving in $20 \mathrm{~mL}$ of PB (10 mM). $20 \mu \mathrm{L}$ of stock Griess reagent solution was added to a $47.10 \mu \mathrm{M}$ solution of Amp-NTA in methanol $(2 \mathrm{~mL})$. UV-Vis spectra were recorded every $10 \mathrm{~min}$ after irradiation with light. The increase in absorbance at $510 \mathrm{~nm}$ indicates the formation of an azo dye which proves the release of NO from Amp-NTA upon photolysis.

\section{Griess assay with Ves-NTA}

$500 \mu \mathrm{L}$ of the Griess stock solution prepared above was added to the Ves-NTA solution of different concentrations in PB $(10 \mathrm{mM})$. 
Five different concentrations $(5.0,12.5,25.0,37.5$ and $50.0 \mu \mathrm{M})$ of Ves-NTA were prepared and UV-Vis spectra were recorded after every $15 \mathrm{~min}$ upon irradiation with blue light $(410 \mathrm{~nm})$ for $2 \mathrm{~h}$. The increase in absorbance at $510 \mathrm{~nm}$ is due to the formation of an azo dye due to the release of a NO radical from Ves-NTA. Furthermore, standard curves were recorded using an aqueous solution of $\mathrm{NaNO}_{2}$ with different concentrations (5-50 $\mu \mathrm{M})$ to estimate the amount of NO released from Ves-NTA.

\section{DAF-FM diacetate assay with Ves-NTA}

To qualitatively detect the release of NO from nanovesicles, a fluorescent probe for NO (3-amino,4 aminomethyl-2', $7^{\prime}$ difluorescein diacetate, DAF-FM DA) has been widely been used. 1.6 $\mu \mathrm{L}$ of DAF-FM DA in DMSO was added to a $5 \mu \mathrm{M}$ solution of Ves-NTA in PB (10 mM). The solution was irradiated with blue light at $410 \mathrm{~nm}$ for $15 \mathrm{~min}$ and emission spectra were recorded thereafter every $15 \mathrm{~min}$ for $3 \mathrm{~h}$. The DAF-FM DA probe is basically nonfluorescent but the fluorescence intensity at $525 \mathrm{~nm}$ increased gradually in every recording after the probe combines with NO to form a fluorescent benzotriazole derivative. ${ }^{22}$

\section{Cytotoxicity studies}

Tetrazolium dye MTT 3-(4,5-dimethylthiazol-2-yl)-2,5-diphenyltetrazolium bromide reduction-based assay was used to evaluate the effect of NO containing lipid vesicles irradiated and non-irradiated at varying concentrations $(1.6 \mu \mathrm{M}, 3.2 \mu \mathrm{M}, 6.4$ $\mu \mathrm{M}, 12.8 \mu \mathrm{M}$ and $32.1 \mu \mathrm{M})$ on cell viability. Cells were cultured in 96 well plates (10 000 cells) with $100 \mu \mathrm{L}$ DMEM complete media (DMEM + 10\% Fetal Bovine Serum (FBS) + 1\% PenStrep) per well and were maintained in a $5 \% \mathrm{CO}_{2}$ incubator at $37^{\circ} \mathrm{C}$. The cells were seeded and maintained for 16 hours. Later, media were replaced with complete media containing Ves-NTA at varying concentrations. After $24 \mathrm{~h}$ of treatment, $100 \mu \mathrm{L}$ of MTT solution ( $1 \mathrm{mg} / 2 \mathrm{~mL}$ ) was added to the cells, and incubated for 4 hours in a $5 \% \mathrm{CO}_{2}$ Incubator. The formed formazan crystals were in $100 \mu \mathrm{L}$ DMSO with incubating for 20 minutes at room temperature on a shaker. The OD value for each well was measured using an ELISA reader at $550 \mathrm{~nm}$.

Percent viability $=\left(A_{550}(\right.$ treated well $)-A_{550}($ empty well $\left.)\right) \div$ $\left(A_{550}(\right.$ control well $)-A_{550}($ empty well $\left.)\right) \times 100$.

\section{Results and discussion}

Incorporation of photoinduced NO releasing molecules into nanomaterials for biomedical applications by conserving the NO releasing ability of the NO donor is a crucial prerequisite for any NO releasing material. Recently, we have reported an easy to make vesicle embedded CO releasing system for effective lighttriggered CO delivery in biological systems. ${ }^{23}$ On this basis, we have decided to use vesicles as a suitable nanomaterial to incorporate a NO releasing photodonor. Chromogenic 4-nitro-3(trifluoromethyl)aniline (NTA) derivatives are known for the photoinduced release of NO under irradiation light. ${ }^{19}$ This compound is stable in the dark and has a suitable absorption coefficient at wavelengths longer than $350 \mathrm{~nm},{ }^{24}$ and these properties make NTA based molecules and materials suitable as NO releasing agents. It inspired us to design a new amphiphilic NO donor $N$-hexadecyl-4-nitro-3-(trifluoromethyl)aniline (AmpNTA) as a suitable amphiphilic molecule to prepare a vesicular NO releasing compound (Ves-NTA), which contains a NTA moiety. Amp-NTA was synthesized in good yield through a single-step reaction between hexadecylamine and 5-chloro-2nitrobenzotrifluoride under reflux conditions and characterized by standard analytical methods such as ${ }^{1} \mathrm{H}-\mathrm{NMR},{ }^{13} \mathrm{C}-\mathrm{NMR},{ }^{19} \mathrm{~F}$ NMR and ESI-mass analysis (Fig. S1-S4†) (Scheme 1).

The compound Amp-NTA is not water-soluble and soluble only in common organic solvents. Therefore, it is not possible to study the NO release from Amp-NTA under physiological conditions in aqueous solution. Consequently, it has a disadvantage of using as a NO photo-donor for biomedical applications. However, upon incorporation into vesicles, it will become biocompatible. Vesicles are the perfect platform for drug delivery. ${ }^{25}$ NTA incorporated into nano-scale vesicles are not known as a NO-releasing agent. Therefore, we have prepared nano-scale vesicles by incorporating Amp-NTA by a simple film hydration approach.

Accordingly, commercially existing dipalmitoylphosphatidylcholine (DPPC) and the newly prepared NO donor Amp-NTA (10 mol\% with respect to used DPPC) were mixed in $10 \mathrm{mM}$ phosphate buffer at $\mathrm{pH} 7.4$ and vesicular lipid bilayers were prepared by a well-known procedure (see the Experimental section). The multilamellar vesicle suspension has been homogenized by an extrusion method using an extruder fixed with a $100 \mathrm{~nm}$ polycarbonate membrane purchased from Avanti polar lipids. Particle size analysis confirmed that the average dynamic particle size of the vesicles is in the range of 100-150 $\mathrm{nm}$ (Fig. 1A). The vesicle solution is stable in the dark at $6{ }^{\circ} \mathrm{C}$ for 2 weeks. The vesicles exposed to light were unstable and precipitated over a period of 2 days. It is also confirmed that the dilution of the vesicle stock solution did not have much effect on the size of the vesicles (Fig. S5 $\dagger$ ).

Transmission electron microscopy (TEM) images suggested that the vesicle solution contains a mixture of large and small vesicles with the size range of 100-150 nm (Fig. 1B). The individual NO donor units of the obtained vesicles are assumed to be equally distributed in both layers of the liposomal membrane as reported for similar surface-modified vesicles. The incorporation of the NTA unit into the surface of the vesicles is confirmed by the UV-Vis spectrum; the absorption maximum at ca. $380 \mathrm{~nm}$ was comparable with the absorption spectrum of the Amp-NTA unit (Fig. 1C).

Initially, the NO releasing ability of Ves-NTA was investigated by using the UV-Vis absorption spectrum upon continuous

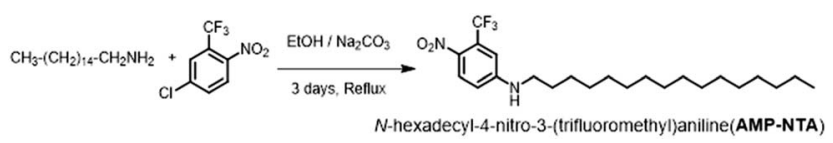

Scheme 1 Synthesis of Amp-NTA. 


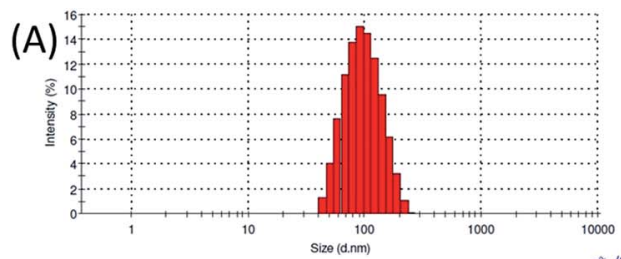

(B)
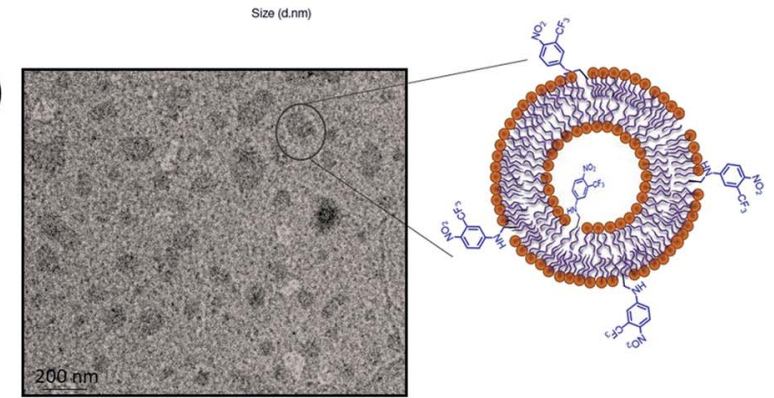

(C)

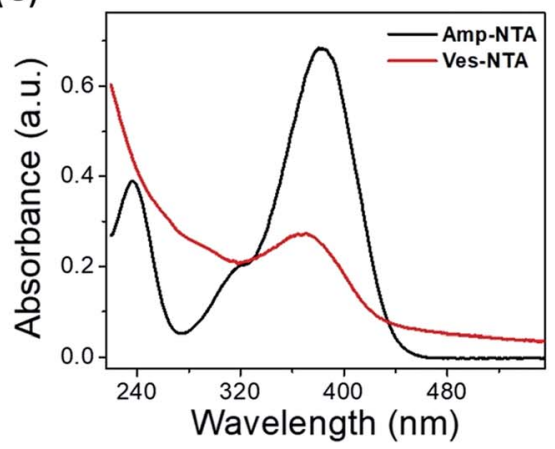

Fig. 1 (A) Particle size distribution curve of Ves-NTA, (B) TEM image of Ves-NTA and (C) UV-Vis spectrum of Amp-NTA and Ves-NTA.

irradiation with light at $410 \mathrm{~nm}$ (Fig. 2). Upon irradiation of VesNTA with light, the UV-Vis spectrum displayed a decreased absorption at $383 \mathrm{~nm}$ along with an increased absorption of a broad band $c a .550 \mathrm{~nm}$. The absorption peaks that appeared at

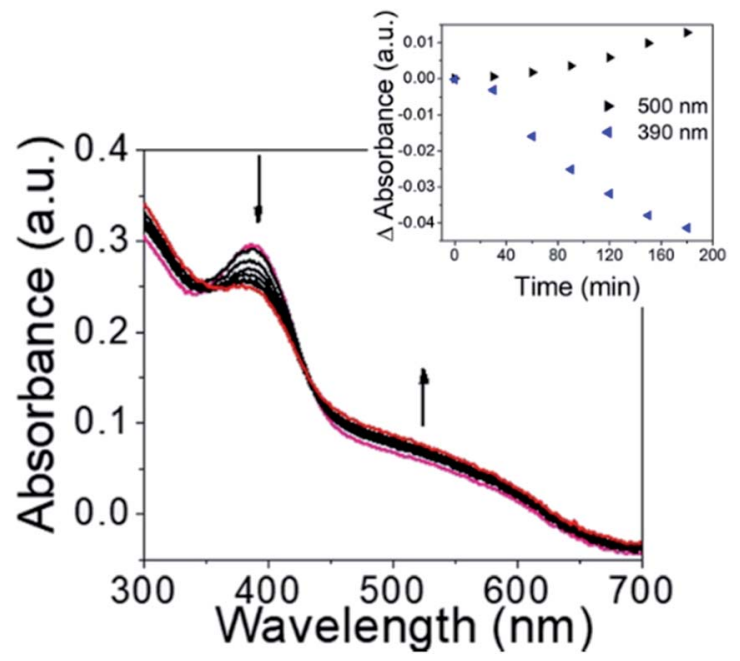

Fig. 2 UV-Vis absorbance spectrum of Ves-NTA upon irradiation with light from 0 to 210 minutes. (Inset) Change in absorbance at $500 \mathrm{~nm}$ and $390 \mathrm{~nm}$ with respect to time.
$383 \mathrm{~nm}$ are the characteristic absorption peaks of the NO donor 4-nitro-3-(trifluoromethyl)aniline. The decrease in absorption with a concomitant increase in absorption at $550 \mathrm{~nm}$ indicates the release of NO through nitro-to-nitrito rearrangement, followed by the formation of a phenol derivative as a stable product that does not have strong absorption in the visible region (Scheme 2). ${ }^{19}$

In Ves-NTA, the ortho position of the nitrobenzene is substituted with a bulky group trifluoromethyl. Due to the steric hindrance from the trifluoromethyl substituents, the nitro group in the ring is fixed almost perpendicular to the aromatic benzene plane. ${ }^{26}$ In this situation, the p orbital of the $\mathrm{NO}_{2}$ group oxygen atom is overlapped with the p orbital of the aromatic ring in both the ground and excited states. Consequently, the release of NO is enabled via nitro-to-nitrito photorearrangement (Scheme 2).

The release of NO under the exclusive control of light inputs was obtained through a nitro $\left(\mathrm{NO}_{2}\right)$ to nitrito (ONO) rearrangement and generation of non-toxic and weak absorbing photoproducts phenoxy and NO radicals in the visible region. The photobleaching of the UV-Vis absorption band observed is in excellent agreement with the photochemical pathway leading to NO release. In contrast, no obvious change in the UV-Vis spectrum was observed in the absence of light.

Furthermore, NO release was also quantified by Griess assay and fluorescence DAF-FM diacetate assay. According to Griess assay, the release of NO from the donor NO molecules or materials is confirmed by the formation of a chromophoric azoderivative, which has an intense absorbance band at $540 \mathrm{~nm}$ (Fig. 3A) and change in colour (Fig. 3B).

The standard protocol of Griess assay ${ }^{27}$ was used to estimate the amount of NO released from Ves-NTA (ESI $\dagger$ ). Accordingly, a stock solution of the Griess reagent was prepared by dissolving an $800 \mathrm{mg}$ reagent in $20 \mathrm{~mL}$ of $\mathrm{PB}(10 \mathrm{mM}) .500 \mu \mathrm{L}$ of this solution was added to the Ves-NTA solution of different concentrations in PB buffer (10 mM). As shown in Fig. 4A, five

(A)

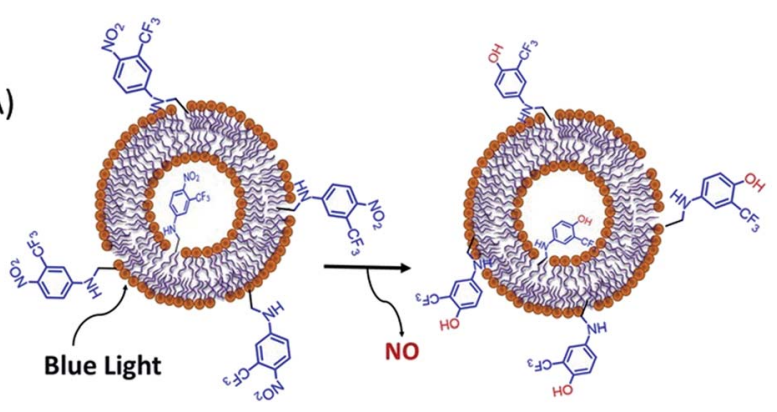

(B)

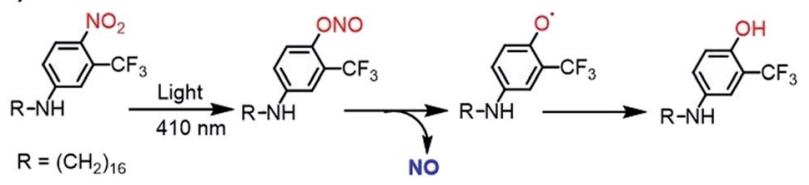

Scheme 2 (A) Schematic representation of NO release from Ves-NTA upon exposing with light and (B) proposed NO releasing reaction mechanism. 
(A)

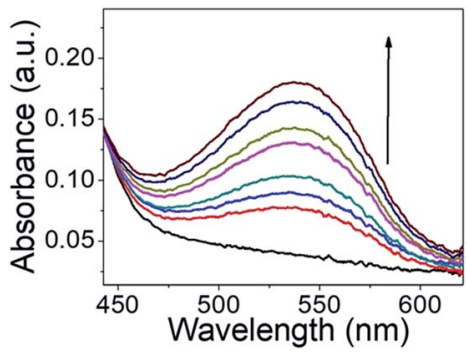

(B)

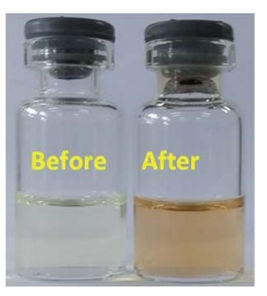

Fig. 3 (A) Griess assay of Ves-NTA $(50 \mu \mathrm{M})$ with the Griess reagent and (B) colour change of the Griess reagent in the presence of Ves-NTA before and after NO release.

different concentrations of Ves-NTA were used and UV-Vis spectra were recorded at regular time intervals upon irradiation with light $(410 \mathrm{~nm})$ and monitored for $2 \mathrm{~h}$.

An increase in absorbance at $540 \mathrm{~nm}$ and a change in the colour of the solution suggest the formation of an azo dye due to the release of a NO radical from Ves-NTA (Fig. 3A). Furthermore, standard curves were recorded using an aqueous solution of
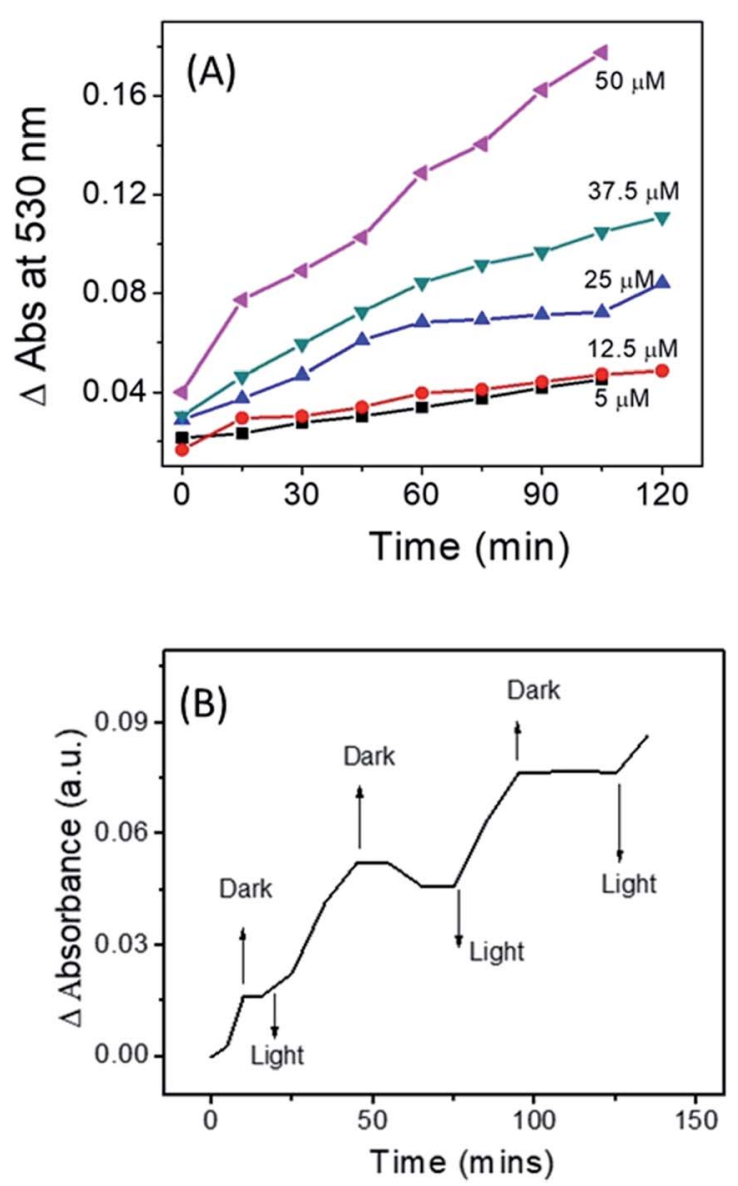

Fig. 4 (A) Change in UV-Vis absorbance at $390 \mathrm{~nm}$ with respect to time for different concentrations of Ves-NTA and (B) NO release profile of Ves-NTA with respect to light ON and OFF.
$\mathrm{NaNO}_{2}$ with different concentrations $(5-50 \mu \mathrm{M})$ to estimate the amount of NO release (Fig. S6 and $\mathrm{S} 7 \dagger$ ).

The calculated amount of NO released from different concentrations of Ves-NTA solutions is listed in Table 1. It is evident from the table that by increasing the concertation of vesicles from 5-50 $\mu \mathrm{M}$ the amount of NO release can be controlled and modulated (Fig. S8 $\uparrow$ and Table 1). These data confirm the formation of NO in water and the regulation of the NO releasing amount by varying the concentration of vesicle solution (Fig. 4A). The NO release profile was also measured by repeated exposure of light and dark, and these experiments clearly demonstrate the light-dependent NO release behaviour of Ves-NTA (Fig. 4b). It indicates that the vesicle embedded NTA releases NO efficiently under aqueous conditions only under light.

In order to validate Griess assay and also to detect low levels of NO released from Ves-NTA, we have used an alternative fluorescence method called as DAF assay. This is another significant procedure for the fluorescence detection of NO in real time; this method uses $o$-diamino aromatic indicators under aerobic conditions. ${ }^{28}$ These indicators react with NO released from NO donors to produce fluorescent triazole derivatives. Among the various $o$-diamino aromatics, fluorescein derivatives 4,5-diaminofluorescein (DAF-2) and 4-amino-5methylamino-2', $7^{\prime}$-difluorofluorescein (DAF-FM DA) are wellknown probes for the detection of NO in aqueous solution.

These probes are used to detect and quantify low concentrations of NO. Basically, DAF-2 and DAF-FM DA are nonfluorescent, but the oxidation product of NO reacts with the indicators to form a fluorescent benzotriazole. ${ }^{22,29}$ This mechanism and change in fluorescence have been widely used to measure NO extracellularly and also to measure the NO released from NO donors. ${ }^{30}$

As shown in Fig. 5, upon photoirradiation NO released from Ves-NTA reacts with the non-fluorescent DAF-FM indicator, and the fluorescence intensity was increased gradually in every reading after the indicator combines with the released NO to become fluorescent.

The fluorescence enhancement kept increasing even after irradiation for more than $3 \mathrm{~h}$. It indicated that the emission intensity of the indicator was linearly related to the concentration of Ves-NTA (inset Fig. 5).

We have also compared the NO release rates and conditions with related NO donors. ${ }^{31-33}$ We found that the current vesicle-

Table 1 Amount of NO release in $\mu \mathrm{M}$ with respect to the different concentrations of Ves-NTA

\begin{tabular}{ll}
$\begin{array}{l}\text { Ves-NTA } \\
(\mu \mathrm{M})\end{array}$ & Amount of NO released ${ }^{a}(\mu \mathrm{M})$ \\
\hline 5.0 & 1.25 \\
12.5 & 1.73 \\
25.0 & 3.08 \\
37.5 & 4.34 \\
50.0 & 7.38
\end{tabular}

${ }^{a}$ Calculated from the avg. of three independent measurements $( \pm 5 \%$ error). 


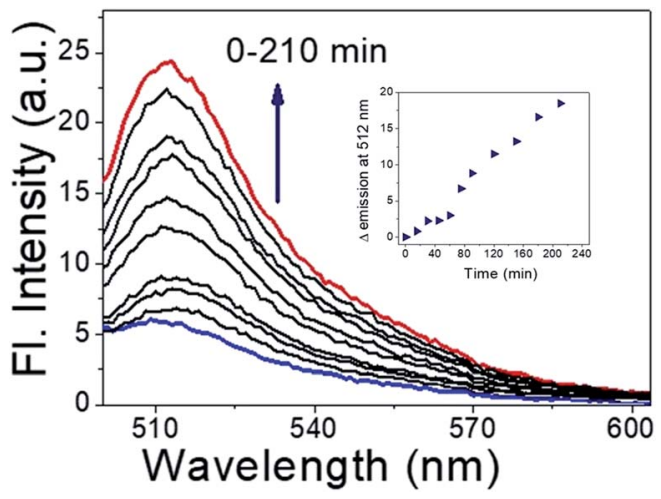

Fig. 5 DAF-FM DA assay for NO release (inset) and kinetics profile of DAF-FM DA assay (time vs. change in Fl. intensity).

based NO releasing system exhibited a comparable rate of $k_{\mathrm{NO}}=$ $0.017 \mathrm{~min}^{-1}$ (Fig. S9†) to the existing NO releasing compounds, with an advantage of water solubility and bio-compatibility. Interestingly, the rate of NO release calculated for Amp-NTA is $k_{\mathrm{NO}}=0.031 \mathrm{~min}^{-1}$ in methanol and is different from that of vesicles (Fig. S10 and S11†). It is also found that there is a difference between the half-lives $\left(t_{1 / 2}\right)$ of vesicles and Amp-NTA. The $t_{1 / 2}$ of Amp-NTA and Ves-NTA $\left(37^{\circ} \mathrm{C}\right.$ at pH 7.4) was found to be 22.0 and $38.5 \mathrm{~min}$, respectively. It shows that vesicles displayed slow NO release. Relative to only Amp-NTA, liposomes exhibited increased NO-release half-lives ( $\sim 2$ times greater). The slow NO release of liposomes may be attributed to the slow photodegradation of the NTA donor in the lipid bilayer membrane in water as compared to the organic solvent medium.

Furthermore, the influence of temperature on the NO releasing behaviour of Ves-NTA was performed at different temperatures such as $27^{\circ} \mathrm{C}, 40^{\circ} \mathrm{C}$, and $70^{\circ} \mathrm{C}$ (Fig. S12 and Table $\mathrm{S} 1 \dagger$ ) by using Griess assay. The results indicate that at higher temperature, the rate of $\mathrm{NO}$ release increases and $t_{1 / 2}$ values decrease. It may be due to fast photodegradation of the NTA unit at higher temperature.

To evaluate the safety profiles of Ves-NTA before and after NO release for phototherapeutic applications, cell viability assay at varying concentrations, $1.6 \mu \mathrm{M}, 3.2 \mu \mathrm{M}, 6.4 \mu \mathrm{M}, 12.8 \mu \mathrm{M}$ and $32.1 \mu \mathrm{M}$, respectively, in Neuro $2 \mathrm{~A}$ cells was performed. Ves-NTA did not affect the cell proliferation pattern at $1.6 \mu \mathrm{M}$ and $3.2 \mu \mathrm{M}$ concentrations compared to the control cells. These liposomes showed $>80 \%$ proliferation at $12.8 \mu \mathrm{M}$ and $>70 \%$ proliferation at $32 \mu \mathrm{M}$ concentration after $24 \mathrm{~h}$ of treatment (Fig. 6), suggesting that Ves-NTA is safe to treat the cells even at higher concentrations as well. Overall, cell viability studies confirm that the NO donor Ves-NTA is non-toxic to the cells before NO release and also after NO is released. After the NO release from Ves-NTA, the remaining expected aromatic phenol product is also not toxic to the cells.

\section{Conclusion}

In summary, we have reported a novel example of a liposome based photo-responsive NO donor Ves-NTA for the controlled

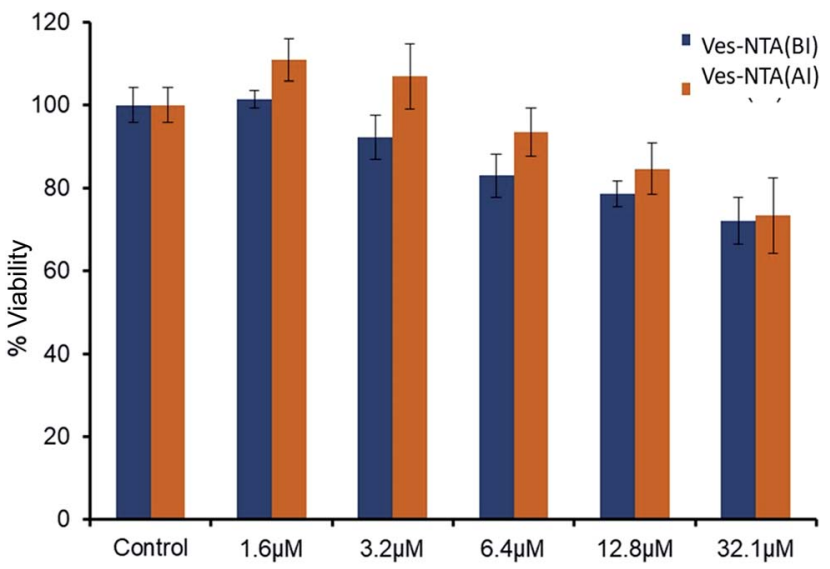

Fig. 6 Cell toxicity studies of Ves-NTA before irradiation (BI) and after irradiation (Al) with light.

release of NO under biological conditions. The synthesis, characterization and NO release kinetics were explained in detail. The nitrobenzene unit (NTA) that is incorporated into the vesicles has multiple functions: (1) it releases NO only under light in a photo-controlled manner, (2) it is non-toxic to the cells before and after the release of NO, and (3) lipids enhance the photo-responsive NO release behaviour, increasing biocompatibility and site-specificity and modulating the NO loading. Using this type of NO-releasing liposome may be a unique strategy and it could be used as an alternative NO donor for therapeutic applications.

\section{Conflicts of interest}

There are no conflicts to declare.

\section{Acknowledgements}

We acknowledge NIT Kurukshetra, Haryana for the research facilities. DAJ acknowledges the financial support of DBT Project No. BT/PR23533/NNT/28/1301/2017.

\section{Notes and references}

1 A. W. Carpenter and M. H. Schoenfisch, Chem. Soc. Rev., 2012, 41, 3742-3752.

2 N. L. Fry and P. K. Mascharak, Acc. Chem. Res., 2011, 44, 289298.

3 J. D. Mase, A. O. Razgoniaev, M. K. Tschirhart and A. D. Ostrowski, Photochem. Photobiol. Sci., 2015, 14, 775785.

4 P. C. Ford, Coord. Chem. Rev., 2018, 376, 548-564.

5 M. C. Frost and M. E. Meyerhoff, J. Am. Chem. Soc., 2004, 126, 1348-1349.

6 J. Pant, M. J. Goudie, S. P. Hopkins, E. J. Brisbois and H. Handa, ACS Appl. Mater. Interfaces, 2017, 9, 15254-15264.

7 R. V. Pinto, A. C. Fernandes, F. Antunes, Z. Lin, J. Rocha, J. Pires and M. L. Pinto, Nitric Oxide, 2019, 90, 29-36. 
8 I. Di Bari, G. Granata, G. M. L. Consoli and S. Sortino, New J. Chem., 2018, 42, 18096-18101.

9 C. A. Joseph, C. W. McCarthy, A. G. Tyo, K. R. Hubbard, H. C. Fisher, J. A. Altscheffel, W. He, R. Pinnaratip, Y. Liu, B. P. Lee and R. M. Rajachar, ACS Biomater. Sci. Eng., 2019, 5, 959-969.

10 C. Bohlender, M. Wolfram, H. Goerls, W. Imhof, R. Menzel, A. Baumgaertel, U. S. Schubert, U. Mueller, M. Frigge, M. Schnabelrauch, R. Wyrwa and A. Schiller, J. Mater. Chem., 2012, 22, 8785-8792.

11 G. Lautner, B. Stringer, E. J. Brisbois, M. E. Meyerhoff and S. P. Schwendeman, Nitric Oxide, 2019, 86, 31-37.

12 D. A. Riccio and M. H. Schoenfisch, Chem. Soc. Rev., 2012, 41, 3731-3741.

13 A. D. Ostrowski, B. F. Lin, M. V. Tirrell and P. C. Ford, Mol. Pharm., 2012, 9, 2950-2955.

14 L.-A. Tai, Y.-C. Wang and C.-S. Yang, Nitric Oxide, 2010, 23, 60-64.

15 D. J. Suchyta and M. H. Schoenfisch, Mol. Pharm., 2015, 12, 3569-3574.

16 F. P. Rodrigues, Z. A. Carneiro, P. Mascharak, C. Curti and R. S. da Silva, Coord. Chem. Rev., 2016, 306, 701-707.

17 S. Sortino, Chem. Soc. Rev., 2010, 39, 2903-2913.

18 I. Di Bari, R. Picciotto, G. Granata, A. R. Blanco, G. M. L. Consoli and S. Sortino, Org. Biomol. Chem., 2016, 14, 8047-8052.

19 E. B. Caruso, S. Petralia, S. Conoci, S. Giuffrida and S. Sortino, J. Am. Chem. Soc., 2007, 129, 480-481.

20 M. L. Navacchia, A. Fraix, N. Chinaglia, E. Gallerani, D. Perrone, V. Cardile, A. C. E. Graziano, M. L. Capobianco and S. Sortino, ACS Med. Chem. Lett., 2016, 7, 939-943.
21 S. Sortino, J. Mater. Chem., 2012, 22, 301-318.

22 H. Kojima, Y. Urano, K. Kikuchi, T. Higuchi, Y. Hirata and

T. Nagano, Angew. Chem., Int. Ed., 1999, 38, 3209-3212.

23 R. Sakla and D. A. Jose, ACS Appl. Mater. Interfaces, 2018, 10, 14214-14220.

24 M. Malanga, M. Seggio, V. Kirejev, A. Fraix, I. Di Bari, E. Fenyvesi, M. B. Ericson and S. Sortino, Biomater. Sci., 2019, 7, 2272-2276.

25 J. M. Gudbergsson, K. Jønsson, J. B. Simonsen and K. B. Johnsen, J. Controlled Release, 2019, 306, 108-120.

26 T. Suzuki, O. Nagae, Y. Kato, H. Nakagawa, K. Fukuhara and N. Miyata, J. Am. Chem. Soc., 2005, 127, 11720-11726.

27 K. Ghosh, R. Kumar, K. Kumar, A. Ratnam and U. P. Singh, RSC Adv., 2014, 4, 43599-43605.

28 P. N. Coneski and M. H. Schoenfisch, Chem. Soc. Rev., 2012, 41, 3753-3758.

29 N. Nakatsubo, H. Kojima, K. Kikuchi, H. Nagoshi, Y. Hirata, D. Maeda, Y. Imai, T. Irimura and T. Nagano, FEBS Lett., 1998, 427, 263-266.

30 Y. Itoh, F. H. Ma, H. Hoshi, M. Oka, K. Noda, Y. Ukai, H. Kojima, T. Nagano and N. Toda, Anal. Biochem., 2000, 287, 203-209.

31 J. F. Quinn, M. R. Whittaker and T. P. Davis, J. Controlled Release, 2015, 205, 190-205.

32 L. Yang, E. S. Feura, M. J. R. Ahonen and M. H. Schoenfisch, Adv. Healthcare Mater., 2018, 7, 1800155.

33 G. M. L. Consoli, I. Di Bari, A. R. Blanco, A. Nostro, M. D'Arrigo, V. Pistarà and S. Sortino, ACS Med. Chem. Lett., 2017, 8, 881-885. 